\title{
Zoledronic acid: clinical utility and patient considerations in osteoporosis and low bone mass
}

This article was published in the following Dove Press journal:

Drug Design, Development and Therapy

17 November 2010

Number of times this article has been viewed

\author{
Ronald C Hamdy ${ }^{1,2}$ \\ 'Chair, Quillen Chair of Geriatrics \\ and Gerontology, Quillen College \\ of Medicine, East Tennessee State \\ University, ${ }^{2}$ Staff Physician, Mountain \\ Home Veterans' Administration, \\ Tennessee, USA
}

\begin{abstract}
The availability of a once-a-year zoledronic acid infusion heralds a new era in the management of osteoporosis. It virtually eliminates the problem of poor compliance with orally administered bisphosphonates and, because it bypasses the gastrointestinal tract, it is not associated with gastrointestinal side effects. Zoledronic acid is effective for the treatment and prevention of postmenopausal osteoporosis, and for the treatment of osteoporosis in men, and glucocorticoid-induced osteoporosis. When administered within three months of a hip fracture, it reduces mortality and the risk of subsequent fractures. It is remarkably free of serious adverse effects. After administration of the intravenous infusion, about $18 \%$ of bisphosphonate-naïve patients experience an acute-phase reaction, including low-grade temperature, aches, and pains. This is reduced to about $9 \%$ in those who have been treated with oral bisphosphonates, and is further reduced by the concomitant and subsequent administration of acetaminophen. The likelihood and magnitude of the acute-phase reaction is less after the second infusion. Other adverse effects are similar to those encountered with other bisphosphonates. Because it is mostly excreted by the kidneys, zoledronic acid should not be administered to patients with a creatinine clearance less than $35 \mathrm{~mL} / \mathrm{min}$. It should not be administered to patients with hypocalcemia.
\end{abstract}

Keywords: zoledronic acid, zoledronate, osteoporosis, osteopenia, bisphosphonates

\section{Introduction}

The main problem with osteoporosis is that it is a silent disease, frequently unnoticed until a fracture occurs. There are no warning signs. Unfortunately, an osteoporotic fracture is often a life-changing event, and the mortality and morbidity associated with fractures, especially at the hip, is considerable. Regrettably, even under the best circumstances, many patients who have sustained osteoporotic fractures, especially at the hip, are not able to resume their daily activities. Osteoporosis is characterized by a low bone mass and microarchitectural deterioration, resulting in an increased susceptibility to fractures. It is very common, with about $40 \%$ of white women and $13 \%$ of white men aged 50 and older expected to sustain an osteoporotic fracture. ${ }^{1-3}$

The prevalence of osteoporotic fractures in women exceeds the combined prevalence of breast cancer, stroke, heart failure, and myocardial infarction in women. ${ }^{4}$ The estimated economic impact of osteoporosis-related fractures is staggering. In the US in 2005 , over two million fractures were sustained, costing about $\$ 17$ billion. About $70 \%$ of these fractures occur in people aged 65 years and older, and these are responsible for about $87 \%$ of the total cost. ${ }^{5}$ 


\section{Diagnosis of osteoporosis}

Diagnosis of osteoporosis can be established solely based on the presence of fragility, low-trauma, or atraumatic fractures. A fragility fracture is defined as a fracture sustained after falling from a height that does not exceed the body height. Low-trauma or low-energy fractures occur after trauma that would not have been anticipated to result in a fracture. Atraumatic fractures occur spontaneously in the absence of trauma, as may happen while the person is sitting down and suddenly experiences very severe localized back pain as a result of a vertebral compression fracture. It is also possible that, in some instances, an atraumatic hip fracture is responsible for the fall a patient with osteoporosis sustains, as opposed to the fall causing the fracture. It has been suggested that the torque force applied to the femoral neck while the patient is turning may be enough to induce a hip fracture.

Many vertebral compression fractures are asymptomatic, and the patient presents with no severe back pain, only loss of height or kyphosis. The presence of these asymptomatic vertebral compression fractures, however, is also diagnostic of osteoporosis and substantially increases the risk of subsequent vertebral and other fractures.

Osteoporosis can also be diagnosed by bone densitometry of the hip, lumbar vertebrae, or the radius (distal one-third) as per World Health Organization (WHO) guidelines. ${ }^{6}$ A T-score of -2.5 or lower establishes the densitometric diagnosis of osteoporosis. The T-score refers to the number of standard deviations the patient's bone mineral density (BMD) is from the mean compared with that of a healthy young adult reference population of the same gender. Patients with a T-score of -1.0 or higher are classified as having a normal bone density, and those with a T-score less than -1.0 and higher than -2.5 are classified as having osteopenia.

Patients with osteopenia also have an increased fracture risk. It is, however, intuitive that a patient with a T-score of -2.4 has a higher fracture risk than one with a T-score of -1.1, although both are in the same diagnostic category of osteopenia. To estimate the fracture risk better, the WHO released its Fracture Risk Assessment $\left(\mathrm{FRAX}^{\circledR}\right.$ ) tool in February 2008. This tool estimates the probability of an osteopenic patient sustaining a hip or a major osteoporotic fracture within the following 10 years. This probability, expressed as a percentage, is determined based on the BMD and a series of risk factors including current cigarette and alcohol use, glucocorticoid usage, and other factors. ${ }^{7}$ The FRAX $^{\circledR}$ tool is freely available, at no cost, on the Internet. The National Osteoporosis Foundation has issued guidelines recommending that treatment be considered in patients with osteopenia if a threshold is reached, ie, a 3\% and $20 \%$ probability of sustaining a hip or other major fractures, respectively, within the following 10 years. ${ }^{8}$

The ease of diagnosing osteoporosis and selecting patients who need to be treated, and the availability of medication that can significantly alter the natural course of osteoporosis and substantially reduce the fracture risk, mandate that an all-out effort be made to identify patients at risk of sustaining fractures before they actually sustain a fracture. Regrettably, however, many patients who have sustained an osteoporotic hip fracture and had it surgically repaired are not treated for osteoporosis, even though the increased risk of subsequent fractures is well known. The American Orthopaedic Association has developed the Own the Bone ${ }^{\circledR}$ program in an attempt to remedy this situation. ${ }^{9}$

\section{Osteoporosis medications Patients needing treatment}

The final decision to treat or not to treat, and which particular therapy to use, must be the treating clinician's decision, based on the circumstances and needs of the patient. However, as a general rule, it is recommended that the following receive medical treatment:

- Patients with fragility fractures

- Patients with a densitometric diagnosis of osteoporosis (T-score -2.5 or lower at the total hip, femoral neck, lumbar vertebrae, or distal one-third radius)

- Patients with osteopenia and a FRAX ${ }^{\circledR}$ score of $\geq 3 \%$ or $\geq 20 \%$ for hip and other major osteoporotic fractures, respectively.

Secondary causes of osteoporosis should first be identified and corrected, especially hypovitaminosis D. For optimum results, in addition to specific medications, the therapeutic strategy must include an adequate daily calcium and vitamin $\mathrm{D}$ intake, as well as lifestyle changes, such as physical exercise for sedentary patients and the discontinuation of cigarette smoking in smokers. In older patients, the fracture risk is reduced and overall outcome is improved by reducing the risk and impact of falling. Hip protectors may be a useful tool in this arena.

\section{Compliance with medication for an asymptomatic condition}

One important issue to consider is the patient's compliance with long-term intake of a medication for an essentially asymptomatic condition. The very low bioavailability of orally administered bisphosphonates necessitates a stringent routine that often interferes with the patient's regular daily routine, ie, the patient must take the oral bisphosphonate 
while fasting, with a glass of water, and must refrain from eating, drinking, taking any other medication, lying down, or undertaking any activity that may increase the risk of gastroesophageal reflux, for 30 minutes (alendronate or risedronate) or 60 minutes (ibandronate).

Many patients will not comply with this regimen, especially given that patients may often have other medications that need to be taken in the fasting state. Compliance is also low in patients who experience adverse effects, such as the upper gastrointestinal symptoms commonly associated with oral bisphosphonates. Patients with cognitive impairment also may not be able to take the medication exactly as directed. Similarly, in nursing homes and other institutions, it may not be possible to expect the nursing staff to ensure that all patients take the bisphosphonate exactly as they should.

There are ample data to support the poor compliance of patients with intake of oral bisphosphonates and the direct correlation between compliance and improved outcome. ${ }^{10-12}$ The US Surgeon General has indeed identified poor compliance with therapy as a major obstacle in the successful management of osteoporosis and reducing the risk of fractures. ${ }^{13}$ Patients prefer less frequent dosing regimens and intravenous (IV) infusion to the oral intake of bisphosphonates. ${ }^{10,14}$ These are now becoming available.

\section{Chemical structure of bisphosphonates}

All bisphosphonates share the same basic chemical structure of two phosphonic acid molecules linked to a carbon molecule. They also have two side chains which determine the affinity of the bisphosphonate for the calcium phosphate in hydroxyapatite crystals in bone tissue, and determine the extent to which the bisphosphonate inhibits the bone-resorbing activity of osteoclasts by selectively inhibiting the farnesyl pyrophosphate synthase (FPPS) enzyme, the key regulatory enzyme in the mevalonic acid pathway. This prevents downstream protein prenylation which, in turn, inhibits the bone-resorbing activity of osteoclasts, and leads to osteoclast apoptosis. It also interferes with the formation of osteoclasts. ${ }^{15}$ Differences in these two side chains are responsible for the clinical difference observed between the various bisphosphonates. The affinity of zoledronic acid for hydroxyapatite is higher than that of other bisphosphonates, and the inhibition of FPPS is higher than that seen in other bisphosphonates. ${ }^{16}$

\section{Zoledronic acid}

Zoledronic acid has a nitrogen-containing heterocyclic ring as a side chain, and can be administered by IV infusion once a year, virtually eliminating compliance issues. Improved compliance is associated with improved fracture protection. ${ }^{17}$ A cost-effectiveness study conducted in France documented that over a three-year period, zoledronic acid was more cost-effective than current therapeutic strategies when medication cost, medical visits, monitoring, and fracture management are all taken into consideration. ${ }^{18}$

\section{Pharmacokinetics}

Maximum plasma concentrations of zoledronic acid are reached, as expected, at the end of the IV infusion. Blood levels then rapidly decline to less than $10 \%$ at four hours and to less than $1 \%$ at 24 hours after infusion. About $61 \%$ of the administered dose is taken up rapidly by bone tissue, tending to localize in areas of increased turnover rate, and is then slowly released back into the circulation. The remaining $39 \%$ is excreted unchanged via glomerular filtration by the kidneys without a significant component of tubular secretion. ${ }^{19}$ The elimination of zoledronic acid is triphasic, comprising two rapid phases followed by a long terminal elimination half-life of 146 hours. ${ }^{15,20}$

Zoledronic acid clearance is dependent on the patient's creatinine clearance. When compared with subjects having normal renal function (creatinine clearance above $80 \mathrm{~mL} / \mathrm{min}$ ), the area under the concentration curve is about $15 \%$ higher in patients with mild renal impairment (creatinine clearance $50-80 \mathrm{~mL} / \mathrm{min}$ ) and $43 \%$ higher in those with moderate renal impairment (creatinine clearance between $30-50 \mathrm{~mL} / \mathrm{min}$ ). Zoledronic acid administration is not recommended in those with a creatinine level below $35 \mathrm{~mL} / \mathrm{min}$. There is no need to adjust the dose in patients who have a creatinine clearance of $35 \mathrm{~mL} / \mathrm{min}$ or higher. Zoledronic acid does not inhibit the P450 enzyme, and there is therefore no interaction with other medications metabolized via cytochrome P450. ${ }^{21}$ However, caution should be exercised in patients on medications that have the potential of reducing the serum calcium level, such as loop diuretics and aminoglycosides, and potentially nephrotoxic medications, such as nonsteroidal anti-inflammatory compounds.

\section{Pharmacodynamics}

Zoledronic acid selectively inhibits the FPPS enzyme, which leads to a loss of prenylated proteins in osteoclasts and reduced bone resorbing activity. ${ }^{22}$ This is manifested by a reduced concentration of bone resorption markers in the serum and urine.

A subset analysis of patients included in the Health Outcomes and Reduced Incidence with Zoledronic Acid 
Once Yearly-Pivotal Fracture Trial (HORIZON-PFT) showed that when compared with placebo, annual IV infusion of zoledronic acid induced a median decrease of $50 \%$ in betaC-terminal telopeptides of Type 1 collagen (beta-CTx) and a 30\% decrease in bone-specific alkaline phosphatase (ALP) in 604 patients (305 on placebo and 299 on zoledronic acid), and a $56 \%$ decrease in procollagen Type 1 amino-terminal peptides (PINP) in 1245 patients (627 on placebo and 618 on zoledronic acid). In most patients these levels remained within the premenopausal range before the next infusion. Levels below the premenopausal range, however, were seen in $1.7 \%, 17.8 \%$, and $19 \%$ for ALP, CTx, and PINP, respectively. The third infusion of zoledronic acid led to a $60 \%$ reduction of CTx levels within 9-11 days; this was followed by a gradual increase, indicating the persistence of bone resorption in patients receiving zoledronic acid. No association could be found between low PINP levels at the end of the first year and fracture risk. ${ }^{23}$

In another subset of the HORIZON-PFT, 152 patients underwent a bone biopsy at three years. Compared with placebo, patients receiving zoledronic acid had a higher trabecular number, higher trabecular bone volume, decreased trabecular separation, and a trend toward improvement in connectivity density. There were no signs of adynamic bone tissue. $^{24}$

\section{Clinical efficacy Postmenopausal osteoporosis}

Zoledronic acid is effective at reducing the risk of fractures in women with postmenopausal osteoporosis (Table 1). Over a three-year period, the HORIZON-PFT demonstrated a $41 \%$ reduction in the cumulative incidence of hip fractures $(P=0.0024)$, a $70 \%$ reduction of new morphometric vertebral fractures $(P<0.001)$, and a $25 \%$ reduction in nonvertebral fractures $(P<0.001$, see Figure 1$) .{ }^{25}$

Compared with placebo, the changes in BMD induced by zoledronic acid were $6 \%, 5.1 \%$, and $6.7 \%$ in the total hip, femoral neck, and lumbar vertebrae, respectively. Similarly, compared with placebo, the biochemical markers of bone turnover were significantly reduced in the zoledronic acid group. At 12 months, the levels of serum CTx, bone-specific ALP, and N-terminal propeptide of Type I collagen were $59 \%$, $30 \%$, and $58 \%$ lower, respectively, in the zoledronic acid group than in the placebo group ( $P<0.001$ for all groups $){ }^{25}$

The HORIZON-PFT was a double-blind, randomized, placebo-controlled study which included 7736 postmenopausal women between the ages of 65 and 89 years recruited from 239 clinical centers in 27 countries. Patients included in the trial either had a T-score of -2.5 or lower at the femoral neck or a T-score of -1.5 or lower, in addition to radiological evidence of either one moderate vertebral compression fracture or two mild vertebral compression fractures.

Patients were randomly allocated to either a placebo or an active group (zoledronic acid $5 \mathrm{mg}$ ) administered by IV infusion at baseline, year 1, and year 2. The follow-up period was three years. There were two subgroups of patients; in the first (3045 active and 3039 placebo), no concomitant osteoporosis therapy was allowed, and in the second (830 active and 822 placebo), selective estrogen receptor modulators, calcitonin, hormonal replacement therapy, or tibolone were allowed at baseline and during the study.

A subgroup analysis of postmenopausal women aged 75 years and older included in the HORIZON-PFT study showed that zoledronic acid leads to a significant reduction in clinical fractures, emphasizing the effectiveness and potential role of zoledronic acid in the management of osteoporosis in older patients. ${ }^{26}$

Although no head-to-head study with fractures as the endpoint has been conducted, the efficacy of zoledronic acid in reducing hip fractures has been established. ${ }^{27,28}$

\section{Glucocorticoid-induced osteoporosis}

The HORIZON-PFT glucocorticoid-induced osteoporosis (GIO) trial ${ }^{29}$ was a noninferiority study comparing zoledronic acid with oral risedronate, which demonstrated that, at the end of a one-year follow-up period, zoledronic acid was not inferior to oral risedronate ( $5 \mathrm{mg}$ daily orally) in the prevention and treatment of GIO (Table 1). The primary endpoint was the percentage change in BMD at the lumbar spine. Secondary endpoints included the change in BMD at the proximal femur and distal radius, and changes in biochemical bone markers.

Two subgroups of patients were included in this study, ie, those who had been on glucocorticoids for three months or less (prevention subgroup) and those who had been on glucocorticoids for more than three months (treatment subgroup). In the latter subgroup, 545 subjects were included (368 women and 177 men) of mean age 53.0 ( \pm 13.8$)$ years; in the prevention subgroup 288 subjects were included (200 women and 88 men) of mean age $57.2( \pm 15.1)$ years. Overall, $93 \%$ of the enrolled subjects completed the study.

Zoledronic acid increased BMD at the lumbar vertebrae more than risedronate in both the treatment subgroups (by $4.06 \%$, standard error of measurement [SE] 0.28 versus $2.71 \%$, SE 0.28 ) and in the prevention subgroup (2.60\%, SE 0.45 versus $0.64 \%$, SE 0.46). Other bones scanned also showed that zoledronic acid was 


\section{A Morphometric vertebral fracture}

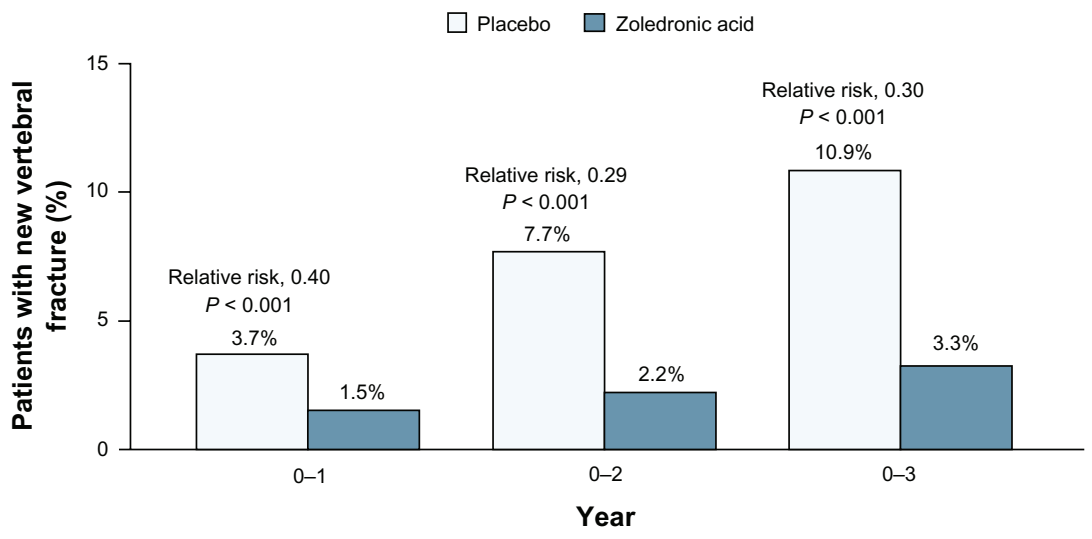

\section{B Hip fracture}

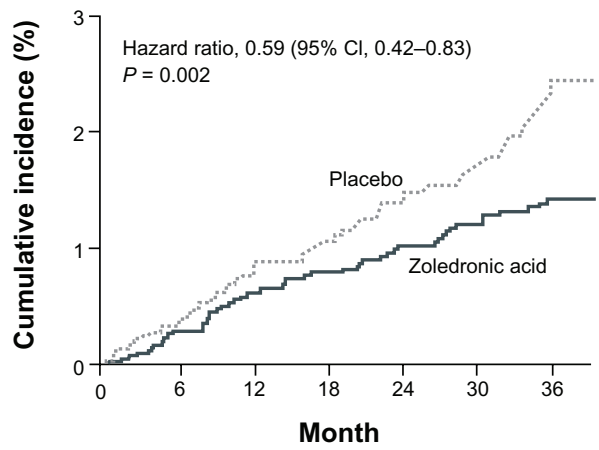

No. at risk

$\begin{array}{llllllll}\text { Zoledronic acid } & 3875 & 3807 & 3674 & 3553 & 3494 & 3387 & 3161\end{array}$ $\begin{array}{llllllll}\text { Placebo } & 3861 & 3806 & 3694 & 3577 & 3499 & 3397 & 3144\end{array}$

\section{Any clinical fracture}

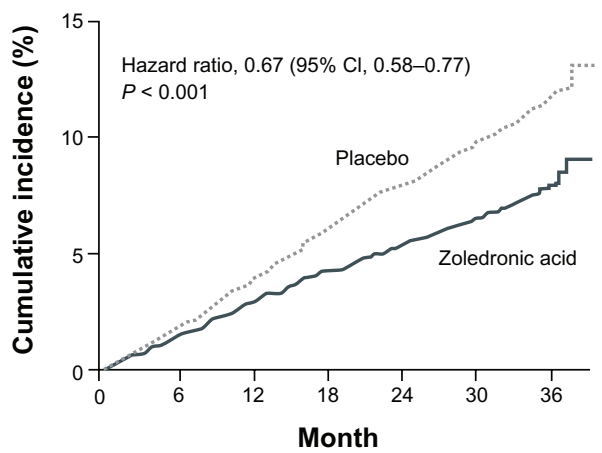

No. at risk

$\begin{array}{llllllll}\text { Zoledronic acid } & 3875 & 3758 & 3585 & 3422 & 3327 & 3189 & 2942\end{array}$

Placebo

\section{Nonvertebral fracture}

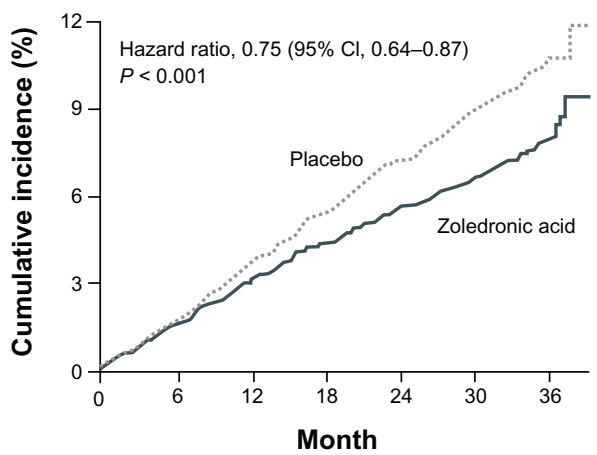

No. at risk

$\begin{array}{llllllll}\text { Zoledronic acid } & 3875 & 3761 & 3586 & 3428 & 3335 & 3201 & 2956\end{array}$ $\begin{array}{llllllll}\text { Placebo } & 3861 & 3759 & 3589 & 3423 & 3299 & 3151 & 2892\end{array}$

\section{E Clinical vertebral fracture}

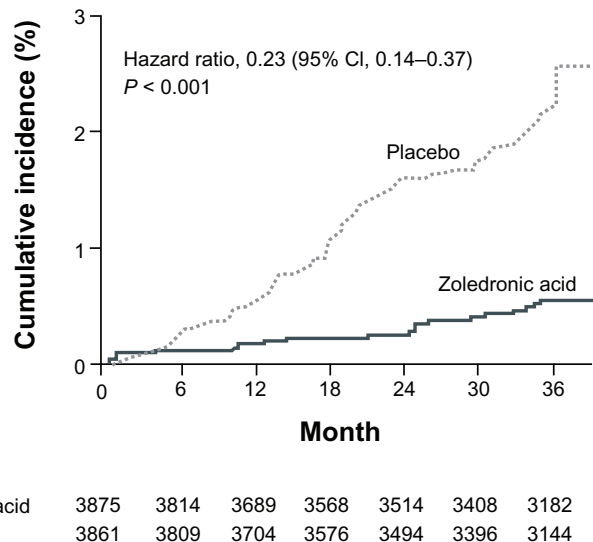

Figure I Incidence of fractures during the 3-year study period. ${ }^{7}$ The primary end points - the incidence of morphometric vertebral fracture (Panel A) and the 3-year incidence of hip fracture (Panel B) - are shown for both groups. In Panel A, the 5675 patients in stratum I who were included in the analysis underwent radiography at baseline and at least once during follow up. Any missing data for earlier visits were imputed from later visits, and missing data for later visits were imputed from earlier visits. The total number of follow up radiographs were 5675 at I year, 5308 at 2 years, and 4969 at 3 years. Secondary end points - nonvertebral fracture (Panel C), any clinical fracture (Panel D), and clinical vertebral fracture (Panel E) - are also shown over a 3-year period. In panels B, C, D, and E, the number of subjects at 36 months is the number who had closeout visits on or after the start of the 36-month window for visits.

Reproduced with permission from Black DM, Delmas PD, Eastell R, et al. Once-yearly zoledronic acid for treatment of postmenopausal osteoporosis. N Engl J Med. 2007;356:1809-1822..$^{25}$ @ 2007 Massachusetts Medical Society. All Rights Reserved.

more effective at increasing BMD than risedronate. The difference between the two treatment groups was evident at six months. Changes in biochemical markers of bone resorption demonstrated that zoledronic acid induced a more substantial inhibitory effect on bone turnover than did risedronate.

Although the overall occurrence of adverse effects was higher in the zoledronic acid group, the frequency of serious 
Table I Indications for zoledronic acid based on selected published studies

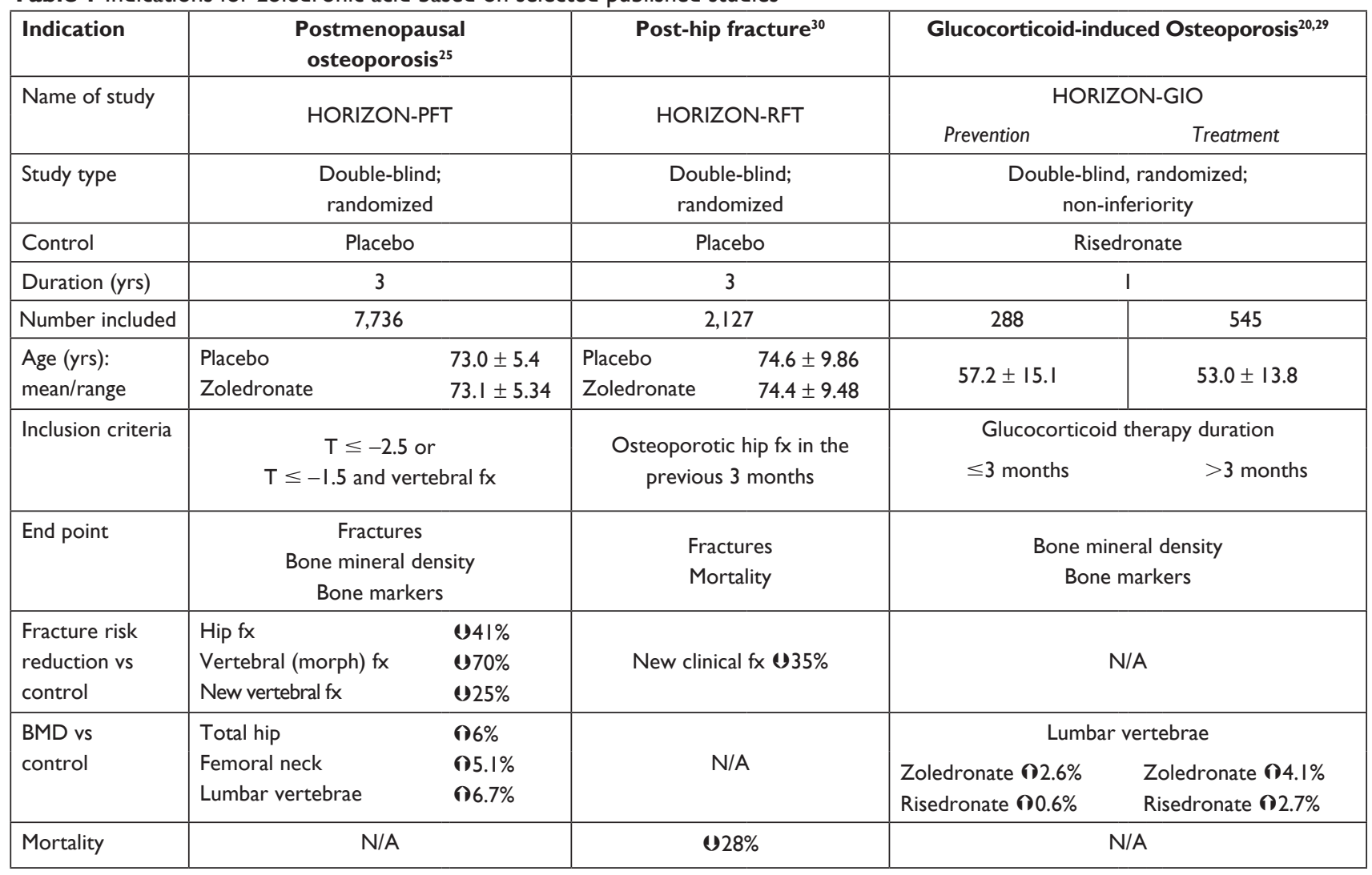

Abbreviations: HORIZON, Health Outcomes and Reduced Incidence with Zoledronic Acid Once Yearly; PFT, Pivotal Fracture Trial; RFT, Recurrent Fracture Trial; GIO, Glucocorticoid-Induced Osteoporosis; fx, fracture; LV, lumbar vertebrae; BMD, bone mineral density; N/A, not applicable.

adverse effects was similar in both drug groups. Many of the patients reported adverse effects associated with zoledronic acid which occurred during the first few days after the infusion, and were consistent with the acute-phase reaction associated with IV administration of large doses of bisphosphonates. Seven deaths occurred during the trial, including four on zoledronic acid and three on risedronate; none was attributed to the study drug. No case of osteonecrosis of the jaw (ONJ) or of delayed or nonunion of fractures was reported.

Annual infusions of zoledronic acid are effective at preventing and treating GIO, and have the advantage of avoiding compliance and other issues associated with the intake of oral bisphosphonates.

\section{Following hip fracture}

Zoledronic acid reduces the rate of fractures in men and women who have sustained an osteoporotic hip fracture (Table 1). The HORIZON-Recurrent Fracture Trial (HORIZON-RFT) studied the effects of administering zoledronic acid to patients who had recently sustained a hip fracture. In this randomized, double-blind, placebo-controlled trial, 2127 patients who had sustained a hip fracture within the past 90 days were randomly allocated to either placebo (1062 patients, 802 women and 260 men) or zoledronic acid (1065 patients, 817 women and 248 men). Mean ages were $74.6( \pm 9.86)$ years and $74.4( \pm 9.48)$ years in the placebo and zoledronic acid groups, respectively. Patients were followed up for a median of 1.9 years. Compared with placebo, patients receiving zoledronic acid had a $35 \%$ reduction $(P=0.001)$ of any new clinical fracture $(1.7 \%$ and $3.8 \%$ in the zoledronic acid and placebo groups, respectively, $P=0.02$ ) and the rates of new nonvertebral fractures were $7.6 \%$ and $10.7 \%$ in the zoledronic acid and placebo groups, respectively $(P=0.03)$. Overall mortality was also significantly less in the zoledronic acid than in the placebo group $(9.6 \%$ and $13.3 \%$, respectively), representing a $28 \%$ mortality reduction $(P=0.01) .{ }^{30}$

A subsequent analysis of the HORIZON-RFT when the time interval between fracture repair surgery and administration of zoledronic acid was taken into account revealed that administration of zoledronic acid two weeks or more after surgical repair of the fracture was associated with significant reductions in clinical vertebral, nonvertebral, and hip fractures, as well as increased hip BMD. ${ }^{31}$ Results of this study point to the possibility of administering zoledronic 
acid to patients hospitalized for hip or other osteoporotic fractures while still in hospital, ${ }^{32}$ thus significantly improving compliance and outcome.

\section{Men with osteoporosis}

Men are not immune to osteoporosis. In fact, the outcome after a hip fracture tends to be worse in men than in women. Current estimates indicate that in the US there are presently at least 14 million men with osteoporosis or low bone mass, and that men sustain about 500,000 osteoporosis-related fractures every year. ${ }^{33}$

A two-year, noninferiority, randomized, multicenter, double-blind, active-controlled clinical trial which included 302 men with osteoporosis (including osteoporosis secondary to hypogonadism) with a mean age of 64 (range 25-86) years showed that zoledronic acid was not inferior to the weekly oral bisphosphonate used (Table 2). At the end of the twoyear follow-up period, the mean increase in lumbar vertebral BMD was $6.1 \%$ and $6.2 \%$ in the zoledronic acid and oral bisphosphonate groups, respectively. The overall mortality and adverse effect were comparable in both groups. ${ }^{20}$

\section{Prevention of postmenopausal osteoporosis}

Zoledronic acid is approved for the prevention of osteoporosis in women with osteopenia (Table 2). The dosage is $5 \mathrm{mg}$ administered by IV infusion every two years. ${ }^{34}$ To assess the usefulness of zoledronic acid in the management of osteopenia, a 24-month, randomized, double-blind, placebo-controlled trial was conducted in 581 postmenopausal women, 45 years of age or older, with evidence of osteopenia as manifested by a T-score less than -1.0 and higher than -2.5 . Zoledronic acid was administered just once at the time of randomization to 181 women and once a year to 198 women, while 202 women received placebo infusions.

Compared with placebo, women receiving zoledronic acid showed a significant increase in BMD of $+5.18 \%$ (95\% confidence interval [CI] 4.64-5.71) and $+4.42 \%(95 \%$ CI 3.87-4.97) in those receiving the annual dose and those receiving the single dose, respectively. Those on placebo infusion sustained a decrease in the BMD at the lumbar vertebrae of $-1.32 \%(95 \%$ CI 1.85-0.80). Significant increases in hip BMD were also noted in women receiving zoledronic acid compared with placebo. As expected, in the women receiving zoledronic acid there was an initial decrease in markers of bone turnover, followed by a gradual partial recovery. Zoledronic acid infusions were well tolerated. The overall incidence of serious adverse events was similar in the three groups, being $10.9 \%, 9.4 \%$, and $11.4 \%$ in the group on zoledronic acid once, zoledronic acid annually, and placebo, respectively. The adverse events were similar to those noted in other larger trials. As expected, the incidence of adverse effects was less after the second dose of zoledronic acid.

Table 2 Indications for zoledronic acid, based on selected as yet unpublished studies

\begin{tabular}{|c|c|c|c|c|}
\hline Indication & Men $^{20,33}$ & \multicolumn{3}{|c|}{ Prevention $20,34,35$} \\
\hline Name of study & Unpublished & \multicolumn{3}{|c|}{ Unpublished } \\
\hline Study type & $\begin{array}{l}\text { Non-inferiority; } \\
\text { randomized }\end{array}$ & \multicolumn{3}{|c|}{$\begin{array}{l}\text { Double-blind; } \\
\text { randomized }\end{array}$} \\
\hline Control & Alendronate $^{*}$ & \multicolumn{3}{|c|}{ Placebo } \\
\hline Duration (yrs) & 2 & \multicolumn{3}{|c|}{2} \\
\hline Number included & 302 & 224 & \multicolumn{2}{|c|}{357} \\
\hline Age & $\begin{array}{c}\text { Mean } 64 \text { years } \\
\text { Range } 25-86 \text { years }\end{array}$ & \multicolumn{3}{|c|}{$\geq 45$ years } \\
\hline Inclusion criteria & & $\begin{array}{c}\text { Osteopenia } \\
<5 \text { yrs postmenopause }\end{array}$ & \multicolumn{2}{|c|}{$\begin{array}{c}\text { Osteopenia } \\
\geq 5 \text { yrs postmenopause }\end{array}$} \\
\hline End point & Bone mineral density & \multicolumn{3}{|c|}{ Bone mineral density } \\
\hline $\begin{array}{l}\text { Fracture risk } \\
\text { Reduction vs control }\end{array}$ & $\mathrm{N} / \mathrm{A}$ & \multicolumn{3}{|c|}{$\mathrm{N} / \mathrm{A}$} \\
\hline BMD vs control & $\begin{array}{ll}\text { Zoledronate } & \mathbf{\$ 6 . 1 \%} \\
\text { Alendronate } & \mathbf{\$ 6 . 2 \%}\end{array}$ & \begin{tabular}{|ll} 
Zoledronate & LV $-\mathbf{D} 4.0 \%$ \\
& Hip $-\mathbf{O} 2.6 \%$ \\
Placebo & LV - (U2.2\% \\
& Hip $-(\mathbf{U} 2.1 \%$
\end{tabular} & $\begin{array}{l}\text { Zoledronate } \\
\text { Placebo }\end{array}$ & $\begin{array}{l}\text { LV - } 14.8 \% \\
\text { Hip - } 2.1 \% \\
\text { LV- } 0.7 \% \\
\text { Hip - U1.0\% }\end{array}$ \\
\hline Mortality & N/A & \multicolumn{3}{|c|}{$\mathrm{N} / \mathrm{A}$} \\
\hline
\end{tabular}

*As cited by Piper ${ }^{33}$ regarding the HORIZON study mentioned in Reclast ${ }^{20}$ which does not name the active control.

Abbreviations: BMD, bone mineral density; LV, lumbar vertebrae; N/A not available. 
Of note, no case of atrial fibrillation (AF), ONJ, or long-term negative effect on renal function was reported. ${ }^{35}$

\section{Bone loss induced by cancer treatment}

A number of medications used in the management of cancer induce bone loss. Osteoporosis may complicate antiestrogen therapy in women with hormone-sensitive breast cancer and androgen deprivation therapy in men with prostate cancer. Zoledronic acid counteracts this bone loss. ${ }^{36}$ It also reduces the skeletal-related events associated with bone metastases in patients with breast or prostate cancer ${ }^{37,38}$ and, in addition, may have specific anticancer activity. ${ }^{37}$

In women with breast cancer, aromatase inhibitors increase bone turnover and reduce bone mass by about 4\%-5\% over a two-year period. Compared with tamoxifen, the risk of fracture is increased by $35 \%-50 \%$ in women treated with aromatase inhibitors. ${ }^{39}$ Several studies have documented the beneficial effect of zoledronic acid in the management of bone loss resulting from therapy for cancer. ${ }^{40-44}$

In a study of 93 men with prostate cancer receiving androgen deprivation therapy, zoledronic acid was shown to increase BMD significantly compared with placebo, regardless of whether the patients had been on androgen deprivation therapy for less or more than one year. In the former group (50 patients), the change in BMD at 12 months was $+5.95 \%$ and $-3.23 \%$ in the zoledronic acid and placebo groups, respectively $(P=0.0005)$. Similarly, among those who had been on androgen deprivation therapy for more than one year, the changes in BMD at 12 months were $+6.08 \%$ and $+1.58 \%$ in the zoledronic acid and placebo groups, respectively $(P=0.0005) .{ }^{45}$ Several other studies have shown comparable results for efficacy of zoledronic acid in men receiving androgen deprivation therapy. ${ }^{46-49}$

\section{Other disease states associated with a low bone mass and osteoporosis}

A number of small studies confirm the efficacy of zoledronic acid in various disease states. Zoledronic acid has been shown to prevent the bone loss seen in 62 adult patients who had received a liver transplant for chronic liver disease. ${ }^{50}$ Zoledronic acid has also been shown to reduce and possibly reverse the bone loss often incurred by stroke victims who develop hemiplegia, especially in the paralyzed side. ${ }^{51-53}$ Additionally, in a study on 30 human immunodeficiency virus (HIV)-infected patients (27 men and 3 women), zoledronic acid was effective at managing HIV-associated osteopenia or osteoporosis. ${ }^{54}$ Zoledronic acid also significantly improved the BMD at the lumbar vertebrae and hips of 54 patients with monoclonal gammopathy of undetermined significance and may be effective for the prevention of fractures in these patients. ${ }^{55}$ Finally, several small studies have confirmed the usefulness of zoledronic acid in the management of osteoporosis in patients with thalassemia. ${ }^{56-58}$

\section{Adverse effects}

\section{Acute-phase reaction}

The acute-phase reaction is characterized by a low-grade fever associated with fatigue, malaise, generalized aches and pains, and, occasionally, bone pain and arthralgia occurring 24-36 hours postinfusion and gradually subsiding over the following 2-3 days. ${ }^{59}$ The acute-phase response is dose-dependent, and occurs mostly after the first infusion of zoledronic acid in a bisphosphonate-naïve patient. It is much less pronounced in subsequent infusions and in patients who have previously taken oral bisphosphonates. ${ }^{60}$ Its severity can also be reduced by administration of acetaminophen 500-1000 mg or paracetamol just before and for 24-48 hours after the infusion (Figure 2). Administration of nonsteroidal anti-inflammatory compounds is not routinely recommended because of the risk of renal impairment. The acute-phase reaction has also been seen following the administration of IV and oral bisphosphonates, albeit to a much lesser extent and degree of severity. ${ }^{61}$ Patients should be made aware of this potential adverse effect and advised to take acetaminophen should symptoms arise.

\section{Musculoskeletal pain}

There have been a few reports of patients experiencing severe incapacitating musculoskeletal pain in the lower back, pelvis, hips, upper legs, and ribs after taking IV or oral (weekly or monthly dose, but not daily dose) bisphosphonates. ${ }^{62}$ The US Food and Drug Administration (FDA) has issued an alert to this effect. ${ }^{63}$ These musculoskeletal pains are different from the acute-phase reaction. Severe musculoskeletal pain can occur at any time after the administration of the bisphosphonate, but tends to improve in many patients after discontinuation of therapy, although it may linger on in some patients, even after discontinuation.

The exact mechanism of these musculoskeletal pains has not been delineated. It could be related to vitamin D deficiency and the compensatory secondary hyperparathyroidism which maintains a high degree of bone turnover and increases the uptake of bisphosphonate in bone, resulting in a higher than average concentration of bisphosphonate in the bone microenvironment. This, in turn, would lead to increased production of interleukin-6 and other proinflammatory cytokines, which 


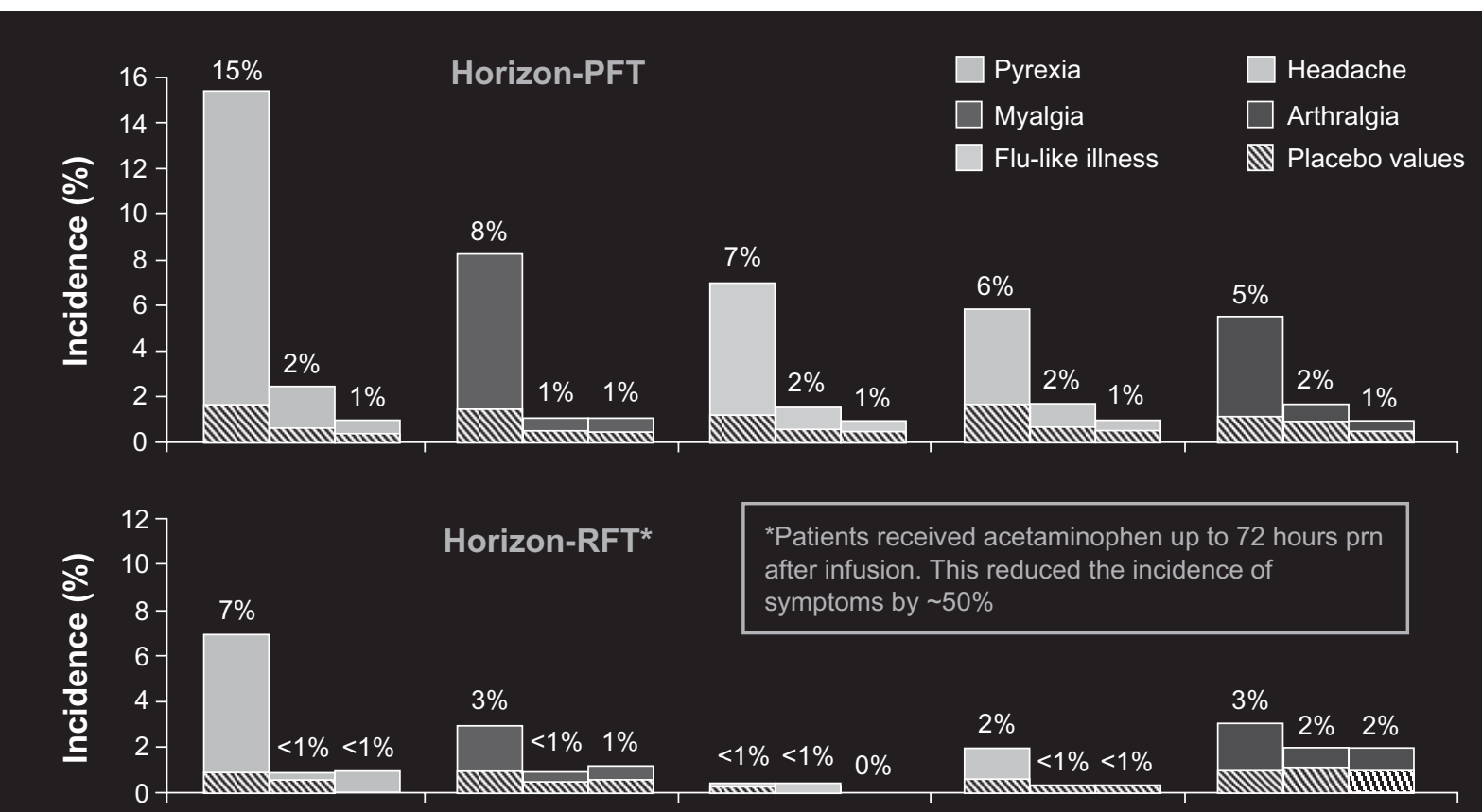

\section{Annual infusion}

1. Data on file. Study ZOL446H2301. Novartis pharmaceuticals corporation.

2. Data on file. Study CZO446L2310. Novartis pharmaceuticals corporation.

Figure 2 Most common adverse events within 3 days after infusion in HORZON PFT and RFT. (Unpublished data. Study ZOL445H230I, Novartis Pharmaceuticals and Study CZOL446L23 I0, Novartis Pharmaceuticals).

Notes: HORIZON PFT, Health Outcomes and Reduced incidence with Zoledronic Acid Once Yearly. Pivotal Fracture Trial: RFT, Recurrent Fracture Trial.

will potentiate the effect of elevated interleukin- 6 due to secondary hyperparathyroidism. ${ }^{58,64}$ Other causes of acute musculoskeletal pain could be related to bisphosphonateassociated synovitis, ${ }^{65}$ flare-up of osteoarthritis, ${ }^{66}$ or acute polyarthritis and myalgia. ${ }^{67}$

\section{Arrhythmias and atrial fibrillation}

In the HORIZON-PFT, arrhythmias occurred in $6.9 \%$ $(\mathrm{n}=266)$ of patients on zoledronate as compared with $5.3 \%$ $(\mathrm{n}=203)$ patients on placebo $(P=0.003) \cdot{ }^{68}$ Serious AF was an unexpected finding, occurring in $50(1.3 \%)$ patients on zoledronic acid as compared with $20(0.5 \%)$ patients on placebo $(P<0.001)$. In $47 / 50$ patients who developed $\mathrm{AF}$, the event occurred more than 30 days after the infusion, excluding the possibility that $\mathrm{AF}$ was due to hypocalcemia or other electrolyte disturbance induced by administration of the bisphosphonate. $^{68}$

Subsequent studies have shown that other bisphosphonates, including alendronate, are also associated with AF. More patients with $\mathrm{AF}$ had previously used alendronate $(6.5 \%)$ than controls $(4.1 \%, P=0.03) .{ }^{69}$ In the HORIZON-RFT, AF was reported in $2.8 \%$ of those receiving zoledronic acid and $2.6 \%$ of those receiving placebo; similarly, serious $\mathrm{AF}$ was reported in $1.1 \%$ and $1.3 \%$ of the treatment and placebo groups, respectively.

Because the HORIZON study (like all other pivotal fracture studies) was not designed to examine the occurrence of AF, doubt could be cast on the reliability of the reported data on $\mathrm{AF},{ }^{70}$ especially given that arrhythmias tend to occur more frequently in older patients. Possible mechanisms by which bisphosphonates may predispose to AF have been described. ${ }^{68}$

On 12 November 2008, a press release from the FDA announced that it could not establish a clear relationship between bisphosphonate therapy and AF, that health care professionals should not alter their prescribing habits for bisphosphonates, and patients should not stop taking these medications because of concern about AF. ${ }^{71}$

\section{Nephrotoxicity}

Annual infusions of zoledronate over a three-year period did not result in any significant deterioration of renal function. ${ }^{25,72}$ There was nevertheless a transient increase in serum creatinine levels of more than $0.5 \mathrm{mg} / \mathrm{dL}$ in $1.3 \%$ of patients on zoledronic acid as opposed to $0.4 \%$ on placebo. Within 30 days, however, the level in more than $85 \%$ of patients had returned to the preinfusion 
level. ${ }^{72}$ Because approximately one-third of the zoledronic acid dose administered IV is excreted by glomerular filtration, it is not recommended to administer this drug to patients who have a creatinine clearance of less than $35 \mathrm{~mL} / \mathrm{min}$. It is also recommended that the IV infusion time be at least 15 minutes.

\section{Atypical fractures of the femoral diaphysis}

There have been several reports of low-trauma fracture of the femoral shaft in patients who have been on long-term (2.5-8 years) bisphosphonate therapy. ${ }^{73-77}$ Bone biopsies revealed excessive suppression of bone turnover, and healing was delayed or absent in many patients. Most of the patients who sustain these fractures experience prodromal thigh pain or vague discomfort for several weeks or months before the fracture occurs, suggesting that the fracture may result from the propagation of a stress fracture that has not been able to heal. The majority of patients who have sustained these fractures also had one or more predisposing factors, such as chronic corticosteroid use, diabetes mellitus, and severe osteoarthritis of the hip or knee. The total incidence of these fractures was 2.5 per 100,000 person-years. The incidence, however, was 0.8 per 100,000 person-years in a population aged 15-60 years and 7.8 per 100,000 person-years for people aged 60 years or older. It has therefore been recommended that patients who have been on bisphosphonate therapy for longer than two years be instructed that pain in the groin or upper thigh may be prodromal of a femoral diaphysis fracture and that they should seek medical help should they experience this pain. ${ }^{60}$

\section{Bisphosphonate-associated osteonecrosis of the jaw}

Several terms are used to refer to this condition, including ONJ, bisphosphonate-related ONJ, bisphosphonate-induced ONJ, and bisphosphonate-associated ONJ. In order to reduce ambiguity and promote international uniformity, an Expert Panel of the American Dental Association recommended use of the term bisphosphonate-associated osteonecrosis of the jaw (BON).

There is still no consensus on the definition of BON. The common denominators of the various proposed definitions include an area of exposed, nonhealing bone in the mandible or maxilla in patients who have been on bisphosphonates and have not received radiation therapy to the jaw. The exposed bone and adjacent area may be asymptomatic or may become secondarily infected. Patients may present with pain, swelling, paresthesia, suppuration, soft tissue ulceration in tissue adjacent to the ragged bony margins of the lesion, intra- and extraoral sinus tracks, loosening of the teeth, and in severe cases, loss of a significant part of the mandible or maxilla. ${ }^{78}$ Whereas the American Society for Bone and Mineral Research (ASBMR), and the American Academy of Oral and Maxillofacial Surgeons (AAOMS) stipulate that the bone should be exposed for at least eight weeks, the American Dental Association (ADA), the Australian and New Zealand Bone and Mineral Society (ANZBMS) and the Medical Oncology Group of Australia stipulate that the bone should be exposed for only six weeks or more. The American Association of Endodontists and the American College of Rheumatology do not stipulate any time limit. The majority of reported cases have followed teeth extraction or other dental procedures, although a few cases have been reported to have occurred spontaneously in patients with osteoporosis treated with oral bisphosphonates. ${ }^{79}$ The ASBMR task force recommends first excluding other common conditions, such as mucositis, gingivitis, periodontal disease, sinusitis, caries infection, and osteomyelitis. ${ }^{80}$

The AAOMS has defined three stages of ONJ: ${ }^{78,81}$ Stage 1, exposed or necrotic bone in asymptomatic patients with no evidence of infection; Stage 2, superimposed infection as evidenced by pain and erythema in the region of the exposed bone, with or without purulent drainage; and Stage 3, same findings as for Stage 2, in addition to pathologic fracture, extraoral fistula, and/or osteolysis extending to the inferior border.

The Expert Panel of the $\mathrm{ADA}^{79}$ concluded that, although still early in the investigative stage, there appears to be a causal relationship between bisphosphonate exposure and BON, as evidenced by the strength of the association (the incidence is higher among individuals on bisphosphonates), temporal association (exposure to bisphosphonates precedes BON), biologic gradient (higher doses are associated with more rapid and serious presentation of BON), consistency (BON has been reported by several investigators), specificity (BON is seen in patients with cancer, osteoporosis, and Paget's disease), and biologic plausibility (BON is defined by the mechanism of action of bisphosphonates, and inhibition of angiogenesis and bone formation after dental extraction).

It is, however, debated whether the initial damage in ONJ starts in the bone and then spreads to the surrounding soft tissues ("inside-out" hypothesis), or whether it starts in the oral epithelium and mucosa, and then spreads to the soft tissue and eventually to bone ("outside-in" hypothesis). ${ }^{78}$ Bisphosphonate toxicity to mucosal cells is well known, as 
evidenced by the gastric, esophageal, and even oral erosions complicating the intake of oral bisphosphonates. ${ }^{82-85}$ It is therefore possible that the pathology starts in the oral mucosa and then spreads to the deeper tissues and bone.

On the other hand, proponents of the inside-out hypothesis suggest that if the rate of bone turnover is substantially reduced, repair of microfissures may be impaired, and this may increase susceptibility to bone necrosis. An antiangiogenic effect of bisphosphonates has been suggested as a possible mechanism leading to BON, whereby interference with blood supply may lead to bone necrosis. ${ }^{86}$ Several studies have documented that bisphosphonates inhibit angiogenesis. ${ }^{87}$ While this explanation is plausible for cases affecting the mandible, it is difficult to explain the relatively frequent involvement of the maxilla with its rich blood supply; $26 \%$ of cases have involved only maxillary bone, and $9 \%$ involved both the maxilla and mandible. ${ }^{88}$ It is possible therefore that the etiology of BON is multifactorial. ${ }^{89}$

Several cases have been reported, mostly among patients with cancer treated with large doses of IV bisphosphonates. A review of $368 \mathrm{BON}$ cases reported in the medical literature for 1996-2006 showed primary diagnoses of multiple myeloma $(n=171)$, metastatic breast cancer $(n=143)$, metastatic prostate cancer $(n=23)$, and other metastatic neoplasia $(n=13)$. Only 18 cases occurred in patients without cancer, ie, three treated for Paget's disease and 15 treated for osteoporosis. In other words, in this large series of 368 patients, only $15(4.1 \%)$ had received bisphosphonates for osteoporosis. ${ }^{88}$

ONJ, defined as exposed bone in the maxillofacial area for more than six weeks with delayed healing despite appropriate care, was observed in two of 7714 patients enrolled in HORIZON-PFT. One patient was in the active group receiving zoledronic acid and the other was in the placebo group. The condition of both patients improved after appropriate antibiotic therapy, debridement, or both. ${ }^{90}$ The investigators concluded that BON is rare in otherwise healthy postmenopausal osteoporotic women treated with zoledronic acid, and that there is no evidence to suggest that these patients need any special treatment beyond routine dental care, or to support altering standard treatment guidelines. An examination of the oral cavity before prescribing bisphosphonates is prudent and does not have to be conducted by a dental professional.

A reduced rate of bone turnover, as evidenced by low serum bone markers levels, such as serum beta-CTx, may predispose to ONJ, and therefore assaying these levels may be helpful in identifying patients susceptible to $\mathrm{BON} .{ }^{91}$ On the other hand, cases of BON have been reported in patients with normal CTx levels, ${ }^{92}$ and the presently available data do not support the use of serum CTx to assess the risk of BON. ${ }^{61}$

The exact risk of developing $\mathrm{BON}$ is not known. In a prospective study in Australia where cases were identified based on the presence of exposed bone for six weeks or more and verification of drug prescriptions, the incidence associated with oral alendronate use was in the range $0.01 \%-0.04 \%$, and this risk was increased by more than four-fold in patients undergoing dental extraction. The median time of alendronate use prior to onset of BON was two years, ${ }^{93}$ although most cases occur after prolonged therapy. Risk factors predisposing to $\mathrm{BON}$ include advanced age, corticosteroid use, rheumatoid arthritis, diabetes mellitus, tooth extraction, invasive dental procedures, and smoking. ${ }^{94}$ The majority of reported $\mathrm{BON}$ cases occurred in patients receiving large doses of IV bisphosphonate as part of cancer therapy. The risk/benefit ratio of $\mathrm{BON}$ versus fractures in patients with osteoporosis is in favor of treating such patients, and this should be explained to interested patients. In patients who are about to undergo major dental work, it is prudent to postpone the initiation of bisphosphonate therapy until after the dental work has been completed. It is also advisable to examine the gums prior to initiating bisphosphonate therapy. Several task forces and expert panels have developed recommendations for the prevention of BON. ${ }^{81,95,96}$

\section{Ocular adverse effects}

Although rare, ocular inflammation occurs in a small minority of bisphosphonate-treated patients, who may present with ocular pain, photophobia, and/or impaired vision. Nonspecific conjunctivitis is usually benign, self-limiting, and improves without specific therapy. ${ }^{60}$ Uveitis and scleritis, on the other hand, are serious complications. Very few cases of posterior scleritis and anterior uveitis complicating zoledronic acid therapy have been reported. ${ }^{97-101}$ Ocular complications are idiosyncratic, and may occur shortly after, or weeks, months, or even years after the initiation of bisphosphonate therapy. ${ }^{61,102}$ Given the potential implications of these conditions, urgent ophthalmologic referral is recommended for patients who present with eye symptoms.

\section{Hypocalcemia and secondary hyperparathyroidism}

Nitrogen-containing bisphosphonates are potent inhibitors of osteoclastic bone resorption. By reducing bone resorption, they reduce the mobilization of calcium from bones to the circulation. Their administration therefore may lead to hypocalcemia, which in turn leads to secondary hyperpara- 
thyroidism, which increases renal tubular calcium resorption and activates the 1-alpha hydroxylase enzyme in the kidneys. The 25-hydroxyvitamin D in the kidneys is then hydroxylated to 1,25 dihydroxyvitamin $\mathrm{D}$ as a compensatory method of increasing the gastrointestinal absorption of calcium, thus restoring serum calcium levels to the normal range.

Patients with hypovitaminosis D, parathyroid dysfunction, or renal failure may not be able to correct the hypocalcemia, which then becomes symptomatic. It is therefore important to ensure that patients about to be administered a bisphosphonate, especially via the IV route, are not vitamin D-deficient and that they have an adequate daily intake of calcium and vitamin $\mathrm{D}$. If there are any concerns, it may be prudent to assay serum 25-hydroxyvitamin D, parathyroid hormone, calcium, and phosphorus levels. Bisphosphonate-induced hypocalcemia and secondary hyperparathyroidism may be avoided or attenuated by the administration of vitamin D and calcium supplements. Secondary hyperparathyroidism should be avoided, especially in patients with cancer, because parathyroid hormone may promote tumor growth. ${ }^{103}$

\section{Upper gastrointestinal adverse effects}

Upper gastrointestinal adverse effects are one of the main factors limiting the use of oral bisphosphonates. Because zoledronic acid is IV administered, it bypasses the gastrointestinal tract, so these adverse effects are rarely seen.

\section{Practical points Indications and dosage}

Zoledronic acid is approved for the treatment and prevention of postmenopausal osteoporosis, osteoporosis in men, GIO, and prevention of a second hip fracture in patients who have sustained a first hip fracture. The treatment dose is $5 \mathrm{mg}$ IV annually, and the prevention dose is $5 \mathrm{mg}$ IV every other year. Contraindications include:

- Hypocalcemia at the time of infusion

- Hypersensitivity to zoledronic acid, any bisphosphonate, or any components of zoledronic acid

- Patients with a creatinine clearance less than $35 \mathrm{~mL} / \mathrm{min}$

- Pregnant or nursing mothers

- Patients on other forms of zoledronic acid

\section{Administration}

Zoledronic acid $5 \mathrm{mg}$ in $100 \mathrm{~mL}$ aqueous solution should be administered by IV infusion via a vented infusion line, administered over at least 15 minutes. Serum calcium and creatinine clearance should be checked prior to the infusion. Patients with hypocalcemia or a creatinine clearance of less than $35 \mathrm{~mL} / \mathrm{min}$ should not receive the infusion. There is no need to adjust the dose for patients with a creatinine clearance above $35 \mathrm{~mL} / \mathrm{min}$. It is also advisable to assay the serum 25-hydroxyvitamin level to ensure the patient does not have hypovitaminosis D. A dental examination should be performed to ensure that the patient is not in need of any major dental work. This does not have to be done by a dental professional. Adequate hydration should be ensured by instructing the patient to drink at least two glasses of water or other fluids before the infusion. Patients, especially bisphosphonate-naïve ones, should be appraised of the possible acute-phase reaction and alerted that taking acetaminophen beforehand might minimize these effects. Administration of acetaminophen following the infusion may reduce the incidence of the acute-phase reaction. Adequate hydration should be maintained, as well as an adequate daily calcium and vitamin D intake.

\section{Conclusions}

The availability and effectiveness of annual zoledronate infusion for the treatment of osteoporosis heralds a new era in the management of osteoporosis, because it virtually eliminates the compliance problem. It is especially helpful if the administration of zoledronic acid can be done at the same time as the patient undergoes some other medical check-up or procedure, such as a bone density scan or mammography.

The positive effect of zoledronate in the prevention of fractures after the patient has sustained a hip fracture introduces the concept of administering it while the patient is hospitalized for an osteoporotic fracture. This will reduce the number of patients who sustain an osteoporotic fracture and are neither diagnosed nor treated for osteoporosis.

The need for an IV infusion may deter a few patients, particularly in geographic areas where IV infusions are not frequently administered, and the patient may need to be referred to a secondary medical center.

Although no head-to-head fracture trial has been performed, the efficacy of zolendrate is at least as good, if not superior, to other treatment modalities. Apart from the acute-phase reaction, the incidence of adverse effects is relatively low and benign. Renal functions are maintained, and atrial fibrillation, although a concern, does not appear to be directly related to the medication. $\mathrm{BON}$ is rare. Patient acceptance of zoledronic acid is good.

\section{Acknowledgment}

Thanks are extended to Ms Lindy Russell for her editorial assistance. 


\section{Disclosure}

The author is a speaker for Eli Lilly and Novartis Pharmaceuticals and a consultant for Amgen.

\section{References}

1. Cummings SR, Melton LJ. Epidemiology and outcomes of osteoporotic fractures. Lancet. 2002;359:1761-1767.

2. Consensus Development Conference 1991. Prophylaxis and treatment of osteoporosis. Am J Med. 1991;90:107-110.

3. NIH Consensus Development Panel on Osteoporosis Prevention, Diagnosis, and Therapy. JAMA. 2001;285:785-795.

4. Riggs BL, Melton LJ III. The worldwide problem of osteoporosis: Insights afforded by epidemiology. Bone. 1995;17 Supp 5:S505-S511.

5. Burge RT, Dawson-Hughes B, Solomon D, et al. Incidence and economic burden of osteoporotic fractures in the United States, 2005-2025. J Bone Miner Res. 2007;34:465-475.

6. WHO Scientific Group on the Assessment of Osteoporosis at the Primary Health Care Level. Summary meeting report. Proceedings of the World Health Organization Meeting 5-7 May 2004, Brussels, Belgium. Available from: http://www.who.int/chp/topics/Osteoporosis pdf. Accessed March 7, 2010.

7. World Health Organization Collaborating Centre for Metabolic Bone Diseases. FRAX ${ }^{\circledR}$ WHO fracture risk assessment tool. Available from: http://www.shef.ac.uk/FRAX ${ }^{\circledR} /$ tool.jsp?locationValue=9. Accessed March 7, 2010.

8. National Osteoporosis Foundation. Clinician's Guide to Prevention and Treatment of Osteoporosis. Washington DC: National Osteoporosis Foundation; 2010. Available from: www.nof.org/physguide. Accessed March 7, 2010.

9. American Orthopaedic Association. Own the Bone. ${ }^{\mathrm{TM}}$ Rosemont, IL: American Orthopaedic Association. Available from: http://www. ownthebone.org/providers. Accessed March 7, 2010.

10. Carmona R, Adachi R. Treatment of postmenopausal osteoporosis, patient perspectives - focus on once yearly zoledronic acid. Patient Pref Adherence. 2009;3:189-193.

11. Lewiecki EM. A clinician's perspective on the use of zoledronic acid in the treatment postmenopausal osteoporosis. J Clin Densitom. 2008;11: 478-484.

12. Siris ES, Selby POL, Saag KG, et al. Impact of osteoporosis treatment adherence on fracture rates in North America and Europe. Am J Med. 2009;122(Suppl 2A):S3-S13.

13. US Department of Health and Human Services. Bone health and osteoporosis: A report of the Surgeon General. US Department of Health and Human Services, Office of the Surgeon General, Rockville, MD [updated 2004 October 14] Available from: http://www.surgeongeneral.gov/library/bonehealth/. Accessed March 7, 2010.

14. McClung M, Recker R, Miller P, et al. Intravenous zoledronic acid $5 \mathrm{mg}$ in the treatment of postmenopausal women with low bone density previously treated with alendronate. Bone. 2007;41: $122-128$.

15. Deeks ED, Perry CM. Zoledronic acid: A review of its use in the treatment of osteoporosis. Drugs Aging. 2008;25:963-986.

16. Demontiero O, Duque G. Once-yearly zoledronic acid in hip fracture prevention. Clin Interv Aging. 2009;4:153-164.

17. Cole RE, Harris T. Preventing nonvertebral osteoporotic fractures with extended-interval bisphosphonates: Regimen selection and clinical application. Medscape J Med. 2009 [serial online];11:12. Available from: http://search.medscape.com/medscape-search?queryText=preventing $\%$ 20nonvertebral. Accessed March 7, 2010.

18. Fardellone P, Cortet B, Legrand E, et al. Cost-effectiveness model of using zoledronic acid once a year versus current treatment strategies in postmenopausal osteoporosis. Joint Bone Spine. 2010;77: $53-57$.
19. Perazella MA, Markowtiz GS. Bisphosphonate nephrotoxicity. Kidney Int. 2008;74:1385-1393.

20. Reclast [Package insert]. Novartis Pharmaceuticals, East Hanover, NJ; May 2009. http://www.pharma.us.novartis.com/product/pi/pdf/reclast. pdf. Accessed March 7, 2010.

21. Lambrinoudaki I, Vlachou S, Galapi F, et al. Once-yearly zoledronic acid in the prevention of osteoporotic bone fractures in postmenopausal women. Clin Interv Aging. 2008;3:445-451.

22. Kavanagh KL, Guo K, Dunford JE, et al. The molecular mechanism of nitrogen-containing bisphosphonates as antiosteoporosis drugs. Proc Natl Acad Sci U S A. 2006;103:7829-7834.

23. Delmas PD, Munoz F, Black DM, et al. Effects of yearly zoledronic acid $5 \mathrm{mg}$ on bone turnover markers and relation of PINP with fracture reduction in postmenopausal women with osteoporosis. J Bone Miner Res. 2009;24:1544-1554.

24. Recker RR, Delmas PD, Halse J, et al. Effects of intravenous zoledronic acid once yearly on bone remodeling and bone structure. J Bone Miner Res. 2008;23:6-16.

25. Black DM, Delmas PD, Eastell R, et al. Once-yearly zoledronic acid for treatment of postmenopausal osteoporosis. NEngl J Med. 2007;356: 1809-1822.

26. Boonen S, Black DM, Colon-Emeric CS, et al. Efficacy and safety of a once-yearly intravenous zoledronic acid $5 \mathrm{mg}$ for fracture prevention in elderly postmenopausal women with osteoporosis aged 75 and older. J Amer Geriatr Soc. 2010;58:292-299.

27. MacLean C, Newberry S, Maglione M, et al. Systematic review: Comparative effectiveness of treatments to prevent fractures in men and women with low bone density or osteoporosis. Ann Intern Med. 2008;148:197-213.

28. Bilezikian JP. Efficacy of bisphosphonates in reducing fracture risk in postmenopausal osteoporosis. Am J Med. 2009;122(Suppl 2): S14-S21.

29. Reid DM, Devogelaer JP, Saag K, et al; HORIZON investigators. Zoledronic acid and risedronate in the prevention and treatment of glucocorticoid-induced osteoporosis (HORIZON): A multicenter, double-blind, double-dummy, randomized controlled trial. Lancet. 2009;373:1253-1263.

30. Lyles KW, Colon-Emeric CS, Magaziner JS, et al. Zoledronic acid and clinical fractures and mortality after hip fracture. N Engl J Med. 2007; 357:1799-1809.

31. Eriksen EF, Lyles KW, Colon-Emeric CS, et al. Antifracture efficacy and reduction of mortality in relation to timing of the first dose of zoledronic acid after hip fracture. J Bone Miner Res. 2009;24:1308-1313.

32. Compston J. Treatments for osteoporosis - looking beyond the HORIZON [Editorial]. N Engl J Med. 356;18:1878-1880.

33. Piper PK Jr, Gruntmanis U. Management of osteoporosis in the aging male: Focus on zoledronic acid. Clin Interv Aging. 2009;4:289-303.

34. Biannnual IV zoledronic acid (Reclast) for prevention of osteoporosis. The Medical Letter: On Drugs and Therapies. 2009;51(1315):49. Available from: www.medicalletter.org. Accessed March 7, 2010.

35. McClung M, Miller P, Recknor C, et al. Zoledronic acid for the prevention of bone loss in postmenopausal women with low bone mass. Obstet Gynecol. 2009;114:999-1007.

36. Brufsky AM. Zoledronic acid for cancer therapy-induced and postmenopausal bone loss. Expert Opin Pharmacother. 2008;9:1013-1028.

37. Doggrell SA. Clinical efficacy and safety of zoledronic acid in prostate and breast cancer. Expert Rev Anticancer Ther. 2009;9:1211-1218.

38. Polascik TJ, Mouraviev V. Zoledronic acid in the management of metastatic bone disease. Therap Clin Risk Manag. 2008;4:261-268.

39. Body JJ, Bergmann P, Boonen S, et al. Management of cancer treatment-induced bone loss in early breast and prostate cancer - a consensus paper of the Belgian Bone Club. Osteoporos Int. 2007;18: 1439-1450.

40. Brufsky AM, Bosserman LD, Caradonna RR, et al. Zoledronic acid effectively prevents aromatase inhibitor-associated bone loss in postmenopausal women with early breast cancer receiving adjuvant letrozole: Z-FAST Study 36-month follow-up results. Clin Breast Cancer. 2009;9:77-85. 
41. Hines SL, Sloan JA, Atherton PJ, et al. Zoledronic acid for treatment of osteopenia and osteoporosis in women with primary breast cancer undergoing adjuvant aromatase inhibitor therapy. Breast. 2010;19:92-96.

42. Hershman DL, McMahon DJ, Crew KD, et al. Zoledronic acid prevents bone loss in premenopausal women undergoing adjuvant chemotherapy for early-stage breast cancer. J Clin Oncol. 2008;26:4739-4745.

43. Gnant M, Mlineritsch B, Luschin-Ebengreuth G, et al. Adjuvant endocrine therapy plus zoledronic acid in premenopausal women with early-stage breast cancer: 5-year follow-up of the ABCSG-12 bone mineral density substudy. Lancet Oncol. 2008;9: $840-849$.

44. Bundred NJ, Campbell ID, Davidson N, et al. Effective inhibition of aromatase inhibitor-associated bone loss by zoledronic acid in postmenopausal women with early breast cancer receiving adjuvant letrozole: ZO-FAST Study results. Cancer. 2008;112: $1001-1010$

45. Bhoopalam N, Campbell SC, Moritz T, et al. Intravenous zoledronic acid to prevent osteoporosis in a veteran population with multiple risk factors for bone loss on androgen deprivation therapy. J Urol. 2009; 182: 2257-2264.

46. Israeli RS, Rosenberg SJ, Saltzstein DR, et al. The effect of zoledronic acid on bone mineral density in patients undergoing androgen deprivation therapy. Clin Genitourin Cancer. 2007;5: 271-277.

47. Michaelson MD, Kaufman DS, Lee H, et al. Randomized controlled trial of annual zoledronic acid to prevent gonadotropin-releasing hormone agonist-induced bone loss in men with prostate cancer. JClin Oncol.2007; 25:1038-1042.

48. Ryan CW, Huo D, Bylow K, et al. Suppression of bone density loss and bone turnover in patients with hormone-sensitive prostate cancer and receiving zoledronic acid. BJU Int. 2007;100:70-75.

49. Smith MR, Eastham J, Gleason DM, et al. Randomized controlled trial of zoledronic acid to prevent bone loss in men receiving androgen deprivation therapy for nonmetastatic prostate cancer. J Urol. 2003;170 (6 Pt 1):2392-2393.

50. Crawford BAL, Kam C, Pavlovic J, et al. Zoledronic acid prevents bone loss after liver transplantation: A randomized, double-blind, placebocontrolled trial. Ann Int Med. 2006;144:239-248.

51. Hamdy RC, Krishnaswamy G, Cancellaro V, et al. Changes in bone mineral content and density following strokes. Am J Phys Med Rehabil. 1993;72:188-191.

52. Hamdy RC, Moore SW, Cancellaro VA, et al. Long term effects of strokes on bone mass. Am J Phys Med Rehabil. 1995;74:351-356.

53. Poole KES, Loveridge N, Rose CM, et al. A single infusion of zoledronate prevents bone loss after stroke. Stroke. 2007;38:1519-1525.

54. Huang J, Meixner L, Fernandez S, et al. A double-blinded, randomized controlled trial of zoledronate therapy for HIV-associated osteopenia and osteoporosis. AIDS. 2009;23:51-57.

55. Berenson JR, Yellin O, Boccia RV, et al. Zoledronic acid markedly improves bone mineral density for patients with monoclonal gammopathy of undetermined significance and bone loss. Clin Cancer Res. 2008;14:6289-6295.

56. Otrock ZK, Azar ST, Shamseddeen WA, et al. Intravenous zoledronic acid treatment in thalassemia-induced osteoporosis; results of a phase II clinical trial. Ann Hematol. 2006;85:605-609.

57. Voskaridou E, Anagnostopoulous A, Konstantopoulous K, et al. Zoledronic acid for the treatment of osteoporosis in patients with beta-thalassemia: Results from a single-center, randomized, placebocontrolled trial. Haematologica. 2006;91:1193-1202.

58. Perifanis V, Vyzantiadis T, Tziomalos K, et al. Effect of zoledronic acid on markers of bone turnover and mineral density in osteoporotic patients with beta-thalassaemia. Ann Hematol. 2007;86:23-30.

59. Olson K, Van Poznak C. Significance and impact of bisphosphonate induced acute phase responses. J Oncol Pharm Pract. 2007;13: 223-229.

60. Papapetrou PD. Bisphosphonate-associated adverse events. Hormones. 2009;8:96-110
61. Kennel KA, Drake MT. Adverse effects of bisphosphonates: Implications for osteoporosis management. Mayo Clin Proc. 2009;84:632-638.

62. Wysowski DK, Chang JT. Alendronate and risedronate: Reports of severe bone, joint and muscle pain. Arch Intern Med. 2005;165: 346-347.

63. US Food and Drug Administration. Bisphosphonates (marketed as Actonel, Actonel $+\mathrm{Ca}$, Aredia, Boniva, Didronel, Fosamax, Fosamax +D, Reclast, Skelid, and Zometa). Available from: http://www.fda.medwatch/ safety/2008/safety08.htm\#Bisphosphonates. Accessed March 7, 2010.

64. de Torrente da la Jara G, Pecoud A, Favrat B. Musculoskeletal pain in female asylum seekers and hypovitaminosis D3. BMJ. 2004;329: $156-157$.

65. Gwynne Jones DP, Savage RL, Highton J. Alendronate induced synovitis. J Rheumatol. 2008;35:537-538.

66. Werner de Castro GR, Neves FS, de Magalhaes Souza Fialho SC, et al. Flare-up of hand osteoarthritis caused by zoledronic acid infusion. Osteoporos Int. Nov 21, 2009. [Epub ahead of print].

67. Gerster JC. Acute polyarthritis related to once-weekly alendronate in a woman with osteoporosis. J Rheumatol. 2004;31:829-830.

68. Pazianas M, Compston J, Huang CL. Atrial fibrillation and bisphosphonate therapy. J Bone Miner Res. 2010;25:2-10.

69. Heckbert SR, Li G, Cummings SR, et al. Use of alendronate and risk of incident atrial fibrillation in women. Arch Intern Med. 2008;166: 826-831.

70. Recker RR, Lewiecki EM, Miller PD, et al. Safety of bisphosphonates in the treatment of osteoporosis. Am J Med. 2009;122(Suppl 2A): S22-S32.

71. US Food and Drug Administration. The FDA safety information and adverse event reporting program. Available at: www.fda.gov/ medwatch/safety/2008/safety08.htm\#bisphosphonates2. Accessed March 7, 2010.

72. Boonen S, Sellmeyer DE, Lippuner K, et al; for the HORIZON Pivotal Fracture Trial. Renal safety of annual zoledronic acid infusions in osteoporotic postmenopausal women. Kidney Int. 2008;74:641-648.

73. Odvina CV, Zerwekh JE, Rao ES, et al. Severely suppressed bone turnover: A potential complication of alendronate therapy. J Clin Endocrinol Metab. 2005;90:1294-1301.

74. Visekruma M, Wilson D, McKienan FE. Severely suppressed bone turnover and atypical skeletal fragility. J Clin Endocrinol Metab. 2008; 93:2948-2952.

75. Goh SK, Yang KY, Koh JS, et al. Subtrochanteric insufficiency fractures in patients on alendronate therapy: A caution. J Bone Joint Surg (Br). 2007;89:349-353.

76. Neviaser AS, Lane JM, Lenart BA, et al. Low energy femoral shaft fractures associated with alendronate use. J Orthop Trauma. 2008; $22: 346-350$

77. Kwek EB, Gosh SK, Koh JS, et al. An emerging pattern of subtrochanteric stress fractures: A long term complication of alendronate therapy? Injury. 2008;39:231-234.

78. Silverman SL, Landesberg L. Osteonecrosis of the jaw and the role of bisphosphonates: A critical review. Am J Med. 2009;122 suppl 2A: S33-S45.

79. Edwards BJ, Hellstein JW, Jacobsen PL, et al; American Dental Association Council on Scientific Affairs. Dental management of patients receiving oral bisphosphonate therapy - expert panel recommendations. Available from: http://docs.google.com/viewer?a=v\&q=cache:REeDi 89n3XkJ:flouridation.org/prof/resources/topics/topics_osteonecrosis_ bisphosphonate_report.pdf+dental+management+of+patients+receivin $\mathrm{g}+$ bisphosphonate+therapy\&hl=en\&gl=us\&pid=bl\&srcid=ADGEESjB bRbOksrGZtIqeGAgZP8Tad_tR9KwQb_YQa4wM0k1Bb1YuQB0z_ MAR-UKG9o2ZK5HfascML1GoPAQDCWYuwgmeG1iu5CzYRjZi1y0M292RY2VfpM1y3xuzH1uE2L_-vD36Fn\&sig=AHIEtbTxi SSidA6ORxdjmiBtb6esNOa5RQ. Accessed March 7, 2010.

80. Khosla S, Burr D, Cauley J, et al; for the American Society for Bone and Mineral Research. Bisphosphonate-associated osteonecrosis of the jaw: Report of a task force of the American Society for Bone and Mineral Research. J Bone Miner Res. 2007;22:1479-1491. 
81. Advisory Task Force on Bisphosphonate-Related Osteonecrosis of the Jaw, American Association of Oral and Maxillofacial Surgeons. American Association of Oral and Maxillofacial Surgeons position paper on bisphosphonate-related osteonecrosis of the jaws. J Oral Maxillofac Surg. 2007;65:369-376.

82. Demerjian N, Bolla G, Spreux A. Severe oral ulcerations induced by alendronate. Clin Rheumatol. 2000;18:349-350.

83. Krasagakis K, Kruger-Krasagakis S, Ioannidou D, Tosca A. Chronic erosive and ulcerative oral lesions casued by incorrect administration of alendronate. J Am Acad Dermatol. 2004;50:651-652.

84. de Groen PC, Lubbe DF, Hirsch LJ, et al. Esophagitis associated with the use of alendronate. N Engl J Med. 1996;335:1016-1021.

85. Bauer DC, Black D, Ensrud K, et al. Upper gastro-intestinal tract safety profile of alendronate. The Fracture Intervention Trial. Arch Intern Med. 2000;160:517-525.

86. Marx RRE, Sawatari Y, Fortin M, Broumand V. Bisphosphonateinduced exposed bone of the jaws: Risk factors, recognition, prevention and treatment. J Oral Maxillofac Surg. 2005;63:1567-1575.

87. Kimmel DB. Mechanism of action, pharmacokinetic and pharmacodynamic profile, and clinical applications of nitrogen-containing bisphosphonates. J Dent Res. 2007;86:1022-1033.

88. Woo SB, Hellstein JW, Kalmar JR. Narrative [corrected] review: Bisphosphonates and osteonecrosis of the jaw. Ann Intern Med. 2006; 144:753-761.

89. Ruggiero SL, Gralow J, Marx RE, et al. Practical guidelines for the prevention, diagnosis and treatment of osteonecrosis of the jaw in patients with cancer. J Oncol Pract. 2006;2:7-14.

90. Grbic JT, Landesberg R, Lin SQ, et al. Incidence of osteonecrosis of the jaw in women with postmenopausal osteoporosis in the health outcomes and reduced incidence with zoledronic acid once yearly pivotal fracture trial. J Am Dent Assoc. 2008;139:32-40.

91. Marx RE, Cillo JE Jr, Ulloa JJ. Oral bisphosphonate-induced osteonecrosis: Risk factors, prediction of risk using serum CTx testing, prevention and treatment. J Oral Maxillofac Surg. 2007;65: 2397-2410.
92. Lehrer S, Montazem A, Ramanathan L, et al. Normal serum bone markers in bisphosphonate-induced osteonecrosis of the jaws. Oral Surg Oral Med Oral Pathol Oral Radiol Endod. 2008;106:389-391.

93. Mavrokokki T, Cheng A, Stein B, et al. Nature and frequency of bisphosphonate-associated osteonecrosis of the jaws in Australia. J Oral Maxillofac Surg. 2007;65:415-423.

94. Palaska PK, Cartsos V, Zavras A. Bisphosphonates and time to osteonecrosis development. Oncologist. 2009;14:1154-1166.

95. American Dental Association Council on Scientific Affairs. Dental management of patients receiving oral bisphosphonate therapy. Expert Panel recommendations. J Am Dent Assoc. 2006;137:1144-1150.

96. ASBMR Task Force on Bisphosphonate-Associated ONJ. Bisphosphonate-associated osteonecrosis of the jaw: Report of a task force of the American Society for Bone and Mineral Research. J Bone Miner Res. 2007;22:1479-1491.

97. Banal F, Briot K, Ayoub G, et al. Unilateral anterior uveitis complicating zoledronic acid therapy in prostate cancer [letter to the editor]. J Rheumatol. 2008;35:2458-2459.

98. Benderson D, Karakunnel D, Kathuria S, Badros A. Scleritis complicating zoledronic acid infusion. Clin Lymphoma Myeloma Leuk. 2006;7:145-147.

99. El Saghir NS, Otrock ZK, Bleik JH. Unilateral anterior uveitis complicating zoledronic acid therapy in breast cancer. BMC Cancer. 2005;5:156.

100. Kilickap S, Ozdamar Y, Altundag MK, et al. A case report: Zoledronic acid induced uveitis. Med Oncol. 2008;25:238-240.

101. Leung S, Ashar BH, Miller RG. Bisphosphonate associated scleritis: A case report and review. South Med J. 2005;98:733-735.

102. Procianoy F, Procianoy E. Orbital inflammatory disease secondary to a single-dose administration of zoledronic acid for treatment of postmenopausal osteoporosis. Osteoporos Int. 2010;21:1057-1058.

103. Berruti A, Tucci M, Generali D, et al. Management of the side-effects of intravenous bisphosphonates: Targeting the serum parathyroid hormone elevation. Ann Oncol. 2006;17:1854-1855.

\section{Publish your work in this journal}

Drug Design, Development and Therapy is an international, peerreviewed open-access journal that spans the spectrum of drug design and development through to clinical applications. Clinical outcomes, patient safety, and programs for the development and effective, safe, and sustained use of medicines are a feature of the journal, which

\section{Dovepress}

has also been accepted for indexing on PubMed Central. The manuscript management system is completely online and includes a very quick and fair peer-review system, which is all easy to use. Visit http://www.dovepress.com/testimonials.php to read real quotes from published authors. 